\title{
Building a Statewide Computer Science Teacher Pipeline
}

\author{
Helen $\mathrm{H}$. Hu \\ Westminster College \\ Salt Lake City, UT, USA \\ hhu@westminstercollege.edu \\ Thomas Gagne \\ University of Puget Sound \\ Tacoma, WA, USA \\ tgagne@pugetsound.edu
}

\author{
Cecily Heiner \\ Southern Utah University \\ Cedar City, UT, USA \\ cecilyheiner@suu.edu \\ Carl Lyman \\ Utah State Office of Education (retired) \\ Salt Lake City, UT, USA \\ carl.lyman@outlook.com
}

\begin{abstract}
From 2012 to 2015, the number of Utah secondary teachers teaching computer science courses grew from 38 to 164 . This growth was made possible by introducing three new CS teacher endorsements, which reduced the effort required for existing teachers to start teaching CS. Instead of committing to completing five college-level CS courses in two years, an existing but new-to-CS Utah teacher could complete an Exploring Computer Science (ECS) endorsement in half a year. Thanks to changes to high school graduation requirements, students were able to take a CS course without using an elective credit, boosting enrollment and broadening participation. Analysis of ECS teacher surveys and student surveys found surprisingly few differences between CS-experienced teachers and new-to-CS teachers in their ability to teach CS. By the end of the ECS course, even ECS students with low confidence in their own CS abilities believed that anyone could succeed in CS, regardless of their teacher's CS background. All students' interest in taking additional CS classes significantly increased after taking ECS, although CS-experienced teachers had a stronger impact on ECS students with low confidence than new-to-CS teachers. These results suggest that school districts seeking to provide computer science education for all their students can successfully staff their CS classes by supporting existing secondary teachers with no prior CS background with quality CS professional development and mentoring.
\end{abstract}

\section{INTRODUCTION}

In a recent Google-Gallup poll, $71 \%$ of superintendents and $42 \%$ of polled principals cited the lack of qualified teachers as an obstacle to offering computer science (CS) courses in their schools [12]. Like most of the nation, Utah high schools suffer from this CS teacher shortage. During the 2012-2013 school year, only 40 of the 130 public high schools, and 4 of the 40 charter high schools, offered a computer pro-

Permission to make digital or hard copies of all or part of this work for personal or classroom use is granted without fee provided that copies are not made or distributed for profit or commercial advantage and that copies bear this notice and the full citation on the first page. Copyrights for components of this work owned by others than the author(s) must be honored. Abstracting with credit is permitted. To copy otherwise, or republish, to post on servers or to redistribute to lists, requires prior specific permission and/or a fee. Request permissions from permissions@ acm.org.

SIGCSE '17, March 08 - 11, 2017, Seattle, WA, USA

Copyright held by the owner/author(s). Publication rights licensed to ACM. ACM 978-1-4503-4698-6/17/03 .. \$15.00

DOI: http://dx.doi.org/10.1145/3017680.3017788
Figure 1: Utah Teachers Teaching CS Classes from 2007-2016. 9-12th grade students attended between 200250 public high schools and middle schools across Utah during this time. By 2016, more than half of these schools had a CS teacher.

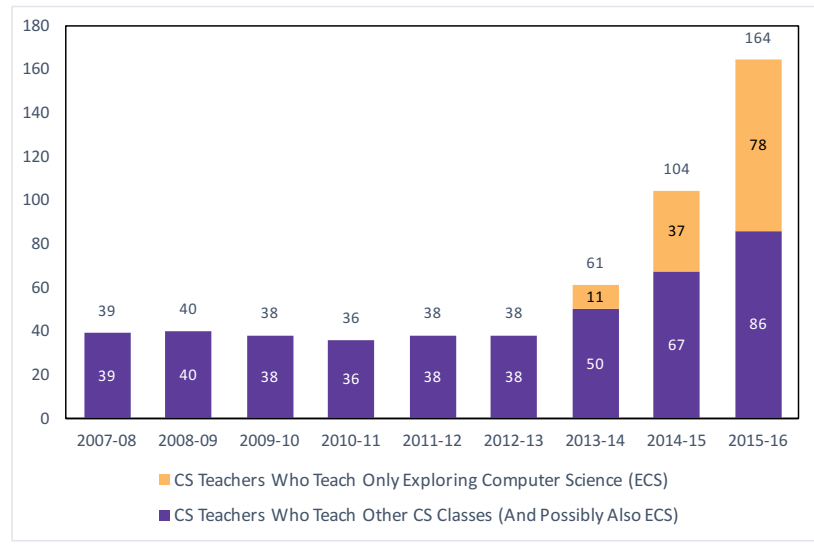

gramming course. Several large Utah school districts offered zero or only one CS course. Some school districts only offered computer programming courses at district technical institutes, which would require students to lose valuable class time to be bussed to the institute from their local high school. In other districts, a few teachers teach CS classes at multiple schools.

To combat this shortage, the authors of this paper created a new in-service CS teacher pipeline in 2013 by introducing an Exploring Computer Science (ECS) course that fulfilled an existing high school graduation requirement for students, while introducing a corresponding ECS endorsement for teachers. (See $[6,8]$ for descriptions of the original full-year and Utah's half-year ECS curriculum.) The ECS endorsement created a low-stakes opportunity for existing teachers to try teaching a new subject area, while the ECS course similarly allowed students to explore a new subject area without using a high school elective. Buoyed by Code.org's Hour of Code marketing, this effort has succeeded in increasing student interest in taking CS classes and in quadrupling the number of Utah CS teachers (see the data from the Utah State Office of Education in Figure 1). Today, several Utah school districts have committed to having a CS teacher in every school, although some are struggling to fill every CS teaching position. 
In 2013, the CSTA completed a comprehensive study of CS teacher certification in the United States and found widespread frustration and confusion [9]. Some states like Georgia have reported that the lack of a CS certification can serve as a challenge to CS education [4], whereas other states with CS certifications viewed the certifications as a barrier to more schools offering CS classes [9]. This paper describes how Utah used a three-tiered CS licensing system to expand its CS teacher pipeline.

High school or secondary level teacher certifications in the United States typically consist of five major components: (1) a set of general education courses (e.g., English, Math, History, and Science courses), (2) a set of general pedagogy courses, (3) a set of subject-related courses for the subject in which they will be teaching (e.g., CS Principles, CS1, CS2), (4) a subject-specific teaching methods course, and (5) a practicum, internship, or other in-classroom probationary teaching experience. Challenges exist in how individual states define which courses meet these sets of requirements and the multitude of pathways that teachers and prospective teachers can take to meet the requirements. The number of pathways and the variations in the requirements are so complex that an extended paper on CS teacher preparation noted "teachers are profoundly confused about the certification requirements in their own states" [5]. The 2013 CSTA report on teacher certification similarly found "The responses within most states show a surprisingly inconsistent perception. Nine states, including some with reasonable numbers of respondents like Colorado, split perfectly down the middle on this question, with exactly 50 percent saying that their state considered Computer Science to be certifiable and the other half taking the opposite view." Consequently, there is much confusion about certification and licensure within individual states as well as across the nation.

\section{COMPUTER SCIENCE STATEWIDE}

In 2015-2016, 183,625 Utah 9-12th graders attended 166 public high schools, 84 public middle schools and 71 charter schools across the state. The Utah State Board of Education sets standards and regulations for courses and teachers in these public and charter schools, but school districts maintain local control in selecting curriculum that meet those standards. Teachers must apply to the state for their endorsement to teach specific courses, and all schools are required to report student enrollment data to the state.

\subsection{Utah High School CS Courses}

Utah high schools have historically offered a two-year sequence of CS classes: Computer Programming I (basic programming concepts) and Computer Programming II (object oriented programming, arrays, and recursion), which have struggled to attract students. After individual high schools failed to enroll enough students to fill their CS teacher's teaching schedule, many school districts shifted their CS courses from the local high schools to district or regional technical institutes specializing in Career and Technical Education (CTE) classes. Any student in the district could enroll in CTE classes at the technical institute, although districts would often impose a requirement that students enroll in two or more CTE classes to offset the travel time between the local high school and the technical institutes. To offer students more CS course options, the technical institutes introduced additional CS classes, such as Game Development
Table 1: 2015-16 Enrollments in CS Classes. 8\% of Utah's 183,625 high school students enrolled in CS classes. The number of high school students earning CS college credit via concurrent enrollment is given in parenthesis.

\begin{tabular}{|c|c|c|}
\hline $\begin{array}{c}\text { Computer Science } \\
\text { Classes }\end{array}$ & $\begin{array}{c}\text { Total } \\
\text { Students }\end{array}$ & $\begin{array}{c}\text { Female } \\
\text { Enrollment }\end{array}$ \\
\hline $\begin{array}{c}\text { Computer } \\
\text { Programming I }\end{array}$ & $\begin{array}{c}3,724 \\
(635)\end{array}$ & $\begin{array}{c}14.4 \% \\
(12.8 \%)\end{array}$ \\
\hline $\begin{array}{c}\text { Computer } \\
\text { Programming II }\end{array}$ & $\begin{array}{c}668 \\
(194)\end{array}$ & $\begin{array}{c}7.5 \% \\
(10.3 \%)\end{array}$ \\
\hline $\begin{array}{c}\text { Computer Science } \\
\text { Principles }\end{array}$ & $\begin{array}{c}331 \\
(23)\end{array}$ & $\begin{array}{c}22.7 \% \\
(4.3 \%)\end{array}$ \\
\hline $\begin{array}{c}\text { Exploring Computer } \\
\text { Science }\end{array}$ & 8,054 & $36.7 \%$ \\
\hline $\begin{array}{c}\text { Game Development } \\
\text { Fundamentals I }\end{array}$ & 1,139 & $14.9 \%$ \\
\hline $\begin{array}{c}\text { Game Development } \\
\text { Fundamentals II }\end{array}$ & 42 & $11.9 \%$ \\
\hline $\begin{array}{c}\text { Other CS } \\
\text { Courses }\end{array}$ & 419 & $10.7 \%$ \\
\hline \hline All CS Classes & 14,377 & $26.7 \%$ \\
\hline
\end{tabular}

and Mobile Development. Typically, offering CS classes at the technical institutes would result in fewer CS teachers overall in the district and would make it less likely that the average student in Utah would take CS classes. In 2012, only $1 \%$ of Utah 9-12 grade students were enrolled in a computer programming class.

The introduction of Exploring Computer Science brought a CS class back to many local high schools, greatly increasing the number of students taking ECS. In 2015-16, all Utah CS classes had a total enrollment of 14,377 students, or $8 \%$ of Utah 9-12 graders (see Table 1). ECS enrolled more than double the number of students than the next most popular CS class, Computer Programming I (8054 ECS students compared to 3724 CP1 students in 2015-16).

The success of the Exploring Computer Science course is related to it serving as one of two options for the high school Computer Technology requirement (the other option was an application-based course on the Microsoft Office Suite). Many high school administrators and guidance counselors were eager to offer their students more than one option for meeting the Computer Technology requirement, which led to the rapid adoption of ECS across the state.

Despite the growth of the ECS course, tying CS courses to high school graduation requirements is generally not sufficient to guarantee high enrollments in CS courses. Computer Programming I and II have long served as math electives that fulfilled the state-level math graduation requirement, which anecdotally attracted a small number of students, but only enough to run Computer Programming I for 397 students in 38 schools and Computer Programming II for 1929 students in 17 schools in 2012. Since 2015, three CS classes (Advanced Placement Computer Science, Computer Programming II, and Computer Science Principles) fulfill a state-level science graduation requirement, but it is too early to draw conclusions whether this change has contributed to higher enrollments in these classes.

Both ECS and CS Principles (CSP) were designed to emphasize the creative aspects of computing and to increase the number of students interested in pursuing additional CS 
classes $[2,6]$. In Utah, both ECS (36.7\%) and CSP (22.7\%) have distinctly higher female participation than other Utah CS classes, all of which had below $15 \%$ female enrollment. ECS and CSP also have racial and ethnic demographics similar to state averages, as is detailed in [8]. We are hopeful that increased enrollment in these two courses will lead to increases in gender and racial diversity in other CS courses soon. Unfortunately female participation in all our CS twocourse sequences remains higher in the first CS course (e.g., $14.4 \%$ in Computer Programming I) than in the second CS course (e.g., 7.5\% in Computer Programming II). Female students already enrolled in CS classes appear to be less likely to enroll in additional CS classes than their male peers.

Relatively few Utah students take the Advanced Placement (AP) Computer Science A exam. Only a select number of Utah high schools offer an AP Computer Science or an International Baccalaureate (IB) Computer Science class (enrolling a total of 118 students in 2015-16). Some number of Computer Programming II students will learn Java and take the AP CS A exam (123 in 2015-16), but a larger number of Utah students are enrolled in the concurrent enrollment courses than take the College Board AP exams (see Table 1). Utah students who enroll in concurrent enrollment courses take a class taught by a local high school teacher following a syllabus developed at a Utah college. Upon passing the high school course, students also receive a grade in the college class. Many Utah teachers, parents and students perceive concurrent enrollment as a smoother path to college credit than AP or IB programs, especially if the student plans to attend an in-state university. In most cases, concurrent enrollment students are learning to program in $\mathrm{C}++$ or Python, and thus are unable to take the AP CS A exam in Java, so few students are able to earn both concurrent enrollment credit and AP or IB credit.

\subsection{CS Endorsements for Secondary Teachers}

Utah teachers complete general education courses, general pedagogy courses, and an in-classroom practicum when they earn their teaching license. Utah teachers must then complete CS-specific courses to earn an CS endorsement, which must be attached to either a secondary (6-12) teaching license or a CTE (Career and Technical Education) license. Tying the CS endorsement to either type of license increases the number of eligible teachers. Prior to 2013, Utah had a single CS endorsement that required CS courses (fulfilled by completing a CS major, a CS minor, or five college level CS courses) and a CS pedagogy course that was not taught at any Utah college.

Existing secondary teachers, or in-service teachers, who wish to teach a new Career and Technical Education (CTE) subject, may apply for a State Approved Endorsement Plan (SAEP) which allows them to teach the subject for two years while completing the endorsement requirements. Prior to the introduction of the multiple levels of CS endorsements, few in-service teachers were able to complete the five collegelevel CS courses originally required for a Computer Science endorsement. Teachers who failed to complete the SAEP within two years were not eligible to apply for a new plan, and would no longer be allowed to teach CS classes until they completed the full endorsement.

In 2013-2014, the Utah State Office of Education replaced the single CS endorsement with three levels of CS endorsement:
- Exploring Computer Science endorsement - certifies a secondary teacher to teach ECS. Requires completing a five-day summer workshop, ongoing professional development in the first year of teaching ECS, a 20-hour Code.org online course and a Certiport test.

- Computer Science Level 1 endorsement - certifies a secondary teacher to teach first year CS classes: Computer Science I, Computer Programming I, and AP Computer Science Principles. Requires completing three college-level CS courses, a CS teaching methods course, and a software development industry exam.

- Computer Science Level 2 endorsement - certifies a secondary teacher to teach all first and second year CS classes, including AP Computer Science, Computer Programming II, Game Development, and Mobile Development. Requires completing everything in the CS Level 1 endorsement, plus two additional college-level CS courses.

Instead of an all-or-nothing CS endorsement, the multiple levels of CS endorsement rewarded teachers who had completed some, but not all, the CS coursework. Teachers who had completed a college level CS1 course in Utah usually had sufficient courses for a CS Level 1 endorsement and could then teach many of the more popular CS courses.

Pre-Service Teachers: The CS state specialist worked with Schools of Education across the state to create clear and reasonable course plans for pre-service teachers (i.e., college students pursuing education certification via a Utah university licensure program). More courses like Web Programming were added to the Computer Science Level 1 course list, offering pre-service teachers the chance to learn a little more programming before taking a college level CS1 course. The authors worked with Schools of Education to create flyers for each program, explaining the course options for earning CS endorsement.

In-Service Teachers: The CS state specialist also added low-cost, primarily-online courses as options for the three college-level CS courses required for CS Level 1 endorsement (Harvard CS50 on edX, Oracle Academy's Java Fundamentals and Oracle Academy's Java Programming). These online options are the most popular path for in-service teachers to complete the CS Level 1 endorsement. Most in-service teachers met the CS-specific pedagogy course by completing the ECS five-day summer workshop, which emphasizes inquiry-based teaching, discussion of CS equity issues, and reflective teaching practice [6]. More recently, Project Lead The Way (PLTW) computer science training and Code.org's AP CSP five-day summer workshop have also been accepted as the CS-specific pedagogy course.

Alternative Routes: In addition to the in-service and pre-service teacher pathways, some number of Utah CS teachers come from industry. Through programs like Microsoft TEALS [7], an industry professional with demonstrated proficiency in CS may teach up to $30 \%$ of a full time teacher equivalent on Letter of Eminence. The school or district must re-submit a request for the Letter of Eminence each school year, with no limit on how many years the same teacher may teach. An industry person on a Letter of Eminence is not required to take any pedagogy classes or other types of certifications. Other industry professionals become full-time CS teachers through the Alternative Route to Licensure (ARL) program, which allows program participants 
to teach full-time at Utah schools for up to three years while completing pedagogy classes, after which they become a secondary teacher and may teach freely.

\subsection{Funding, Sustainability and Partnerships}

The initial growth of Utah CS teachers can be traced to the Utah Exploring Computer Science Initiative, a National Science Foundation CE21 funded project, which provided teachers with $\$ 500$ stipends for attending the ECS workshop and $\$ 1000$ stipends for teaching ECS and attending the ongoing professional development workshops and mentor meetings [8].

In Fall 2015, the Utah State Office of Education and the Utah STEM Action Center created a partnership with Code.org to deliver professional development to Utah CS teachers. Code.org provided and funded all the professional development workshops and half of the teacher stipends with Utah partners funded the remaining half of the teacher stipends through leadership at the Utah STEM Action Center, a government entity created by the state legislature to support the implementation of STEM education best practices in K-12 schools. In Summer 2016, an ECS summer workshop was self-funded by a single school district, and stipends were provided by the district. Teachers from other districts were invited to attend if their districts paid their teachers' stipends. Future funding plans include continuing to transition to district and state legislature funded models for in-service teacher professional development. Several other national organizations have helped to support the development of Utah CS teacher pipeline including the Expanding Computing Education Pathways Alliance (ECEP) [1], and The National Center for Women \& Information Technology (NCWIT) Counselors for Computing $(\mathrm{C} 4 \mathrm{C})$ program [10].

\section{RESULTS}

From 2007-08 to 2012-13 the number of Utah teachers teaching CS was relatively stable. Beginning in 2013, with the start of the Utah Exploring Computer Science Initiative, the number of CS teachers more than quadrupled (see Figure 1), growing from 38 CS teachers in 2012-13 to 164 CS teachers in 2015-16. This increase is not limited to ECS teachers; the number of teachers teaching CS courses requiring a CS Level 1 or Level 2 endorsement increased from 38 in $2012-13$ to 86 by $2015-16$.

The full-time equivalent (FTE) is the number of full-time CS teachers that would be employed if all CS teachers taught exclusively CS courses (see Figure 2). The ratio of FTEs to actual number of CS teachers correlates to how many CS classes are taught by the average CS teacher statewide. Between $2007-2012,39 \%$ to $45 \%$ of Utah's CS teachers' teaching schedules were computer science classes. In other words, the average Utah teacher who taught CS classes spent most of their day teaching non-CS classes. One year before the introduction of ECS, this ratio dropped to $33 \%$, and this ratio has fluctuated little since then. Teachers teaching only ECS courses have a slightly lower ratio than those teachers teaching more advanced CS courses that require CS Level 1 and/or CS Level 2 endorsements (31\% vs 33\% in 2015-16).

Because we have more data for ECS teachers than for Utah CS teachers as a whole, the remainder of Section 3 focuses exclusively on ECS teachers. Of the 150 ECS teachers trained from summer 2013 to fall 2015, 44.4\% are female
Figure 2: Utah CS Teachers' Full Time Equivalents (2007-2016). Most CS teachers spend more time teaching non-CS topics than CS, with surprisingly little difference between teachers teaching ECS only vs teachers teaching other CS classes (possibly including ECS).

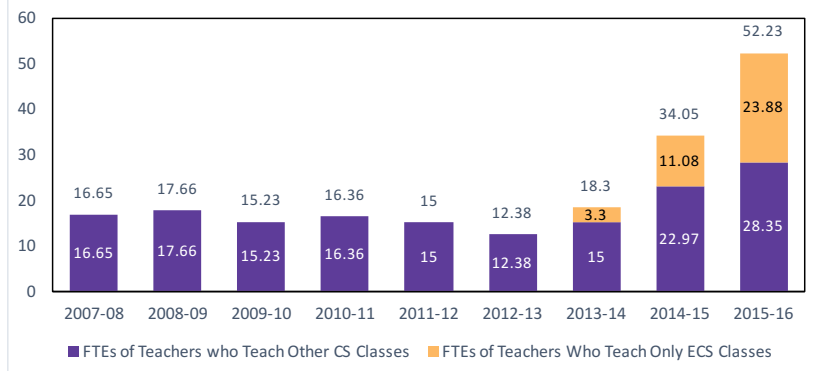

Table 2: Impact of ECS Course on Student Belief that Anybody Can Improve in CS (2015-16)

\begin{tabular}{|c|c|c|c|c|}
\hline $\mathrm{N}$ & $\begin{array}{c}\text { Pre-ECS } \\
\text { Confidence }\end{array}$ & $\begin{array}{c}\text { Pre-ECS } \\
\text { Belief }\end{array}$ & $\begin{array}{c}\text { Post-ECS } \\
\text { Belief }\end{array}$ & $p$ \\
\hline 289 & Low & 3.49 & 4.25 & $p<.001$ \\
\hline 290 & Med & 3.71 & 4.27 & $p<.001$ \\
\hline 290 & High & 4.08 & 4.30 & $p<.001$ \\
\hline
\end{tabular}

(whereas $58.4 \%$ of all secondary teachers statewide are female). $93.3 \%$ of ECS teachers are white (vs 90.5\%), while $4 \%$ are Hispanic (vs 1.7\%) and $3.3 \%$ are American Indian, Alaskan, or Pacific Islander (vs $0.9 \%$ ). Of the 122 teachers who attended an ECS workshop and then started teaching ECS, four retired, three left teaching as a profession, and seven stopped teaching ECS because they switched schools. Of the remaining 108 ECS teachers, two stopped teaching ECS but continued to teach more advanced CS classes, whereas seven $(6.5 \%)$ are no longer teaching any CS classes.

\subsection{Equity in High School CS Courses}

To determine if ECS teachers were encouraging all students in their ECS classes, we asked 2015-2016 ECS students in an end-of-course survey how much they agreed with the statement "Everyone has the potential to significantly improve their computer science abilities". Although students with lower pre-ECS confidence in their own computer science abilities initially disagreed with this statement more strongly than more confident students, by the end of the course all students had significantly increased their agreement with this statement to approximately the same level of $\approx 4.27$ on our Likert scale $(\mathrm{SD}=0.881)$, where 1 indicates "strongly disagree" and 5 indicates "strongly agree". Table 2 summarizes the pre-ECS and post-ECS studentreported agreements with this statement. To remove the confounding effect of student pre-ECS confidence on agreement with this statement, we separated students into three equal-sized groups (low, medium, and high) by taking the average of their self-reported pre-course understanding of CS concepts, separated by the 33rd and 66th percentiles. (Our choice of percentiles is consistent with 1-D $k$-means clustering since student pre-ECS confidence is approximately uniformly distributed and the screeplot bends at three.)

\subsection{New-to-CS vs. CS-Experienced Teachers}

Since our ECS pipeline relies on training teachers with no 
CS experience (only one quarter of 2015-2016 ECS teachers had prior CS experience), we are interested in examining the differences between teachers with and without prior CS experience. With this in mind, we separated 2015-16 ECS teachers into two groups for comparison:

- CS-Experienced Teachers: teachers with a CS degree, experience teaching other CS courses beforehand, or an industry background in CS

- New-to-CS Teachers: teachers with no prior experience studying or teaching CS

In our comparison of these two groups (described in detail in the Sections 3.2.1 and 3.2.2), we found many similarities and few differences between the teachers.

\subsubsection{Teacher-Based Results}

We first examined a survey administered to each 2015-16 teacher before they received any ECS training as well as after they completed their first semester of ECS. All teachers self-reported significant gains in their ability to teach CS concepts ( $p<0.001$ in a one-tailed welch t-test), but only new-to-CS teachers reported significant gains in their ability to teach through inquiry $(p<.001)$ and to use reflective teaching practices $(p=.02)$. We found no significant differences between the gains of these two groups in any other categories $(p>.1$ in two-tailed welch t-tests).

The second survey we examined was administered at the end of a 2015 summer ECS workshop and measured teacher's abilities to teach various topics and use certain teaching strategies both before and after they participated in the workshop. Once again, all teachers reported significant gains in each area $(p<.001$ in a one-tailed welch t-test): CS concepts, inquiry, equity, reflective teaching practices, and understanding of ECS objectives. The only significant difference between new-to-CS and CS-experienced teachers' growths was new-to-CS teachers' greater improvement in understanding of ECS objectives ( $p=.006$ in a two-tailed welch t-test). We were pleased by each group's reported increase in their ability to teach with equity, in which new-toCS teachers increased from 2.66 to 3.90 and CS-experienced teachers increased from 3.00 to 4.19 on our five-point Likert scale (where 1 indicates "minimal skill" and 5 indicates "extensive skill"). These results may explain the findings in Table 2.

In both surveys, CS-experienced teachers reported higher values than new-to-CS teachers for the most areas, indicating a higher level of confidence among CS-experienced teachers. This difference in teacher self-perception has been observed before by $\mathrm{Ni}$ and Guzdial, who previously reported that background and certification are factors that influence how teachers see themselves [11]. Of note, new-to-CS teachers' post-ECS scores for CS concepts were higher than CSexperienced pre-ECS scores for CS concepts.

\subsubsection{Student-Based Results}

We also compared new-to-CS teachers to CS-experienced teachers by examining a survey taken by 2015-2016 ECS students at the end of the course. Students self-reported their pre-course and post-course confidence in various CS concepts on a five-point Likert scale (where 1 indicates "not competent at all" and 5 indicates "perfectly competent"). To remove the confounding effect of student pre-course confi-
Figure 3: Differences in Male and Female Enrollment for ECS Teachers Groups (2015-16). New-toCS teachers enrolled a higher percentage of female students with low, pre-ECS confidence than teachers with prior CS experience.

\begin{tabular}{|c|c|c|c|c|c|c|}
\hline \multicolumn{3}{|c|}{ Male } & \multicolumn{3}{|c|}{ Female } & \\
\hline 123 & 153 & 167 & 90 & 62 & 36 & New-to-CS \\
\hline Low & Med & High & Low & Med & High & \\
\hline 37 & 44 & 56 & 39 & 31 & 31 & CS-experienced \\
\hline
\end{tabular}

dence on improvement levels (e.g. students with greater precourse confidence will have less room to improve), we separated students into the same low/medium/high confidence groups we used in Table 2 . We then separated students by whether their teacher had experience in CS and we found that each skill group had significant gains in confidence regardless of their teacher's CS experience $(p<.05$ in a onetailed t-test) and that no skill group had significantly different levels of improvement between teacher groups $(p>.05$ in a two-tailed t-test). As expected, students from lower skill groups had higher gains than students from higher skill groups. In other words, how much CS content students selfreported learning in ECS appears to be based on how much they believed they knew before taking ECS, and appears to have no correlation to their teacher's CS background.

We did find two areas of differences between new-to-CS and CS-experienced teachers. The first difference was in the student interest in taking more CS courses before and after ECS. Separating again by the groups from Table 2 and by teacher CS experience, we found that all students had significant increases in this interest $(p<0.05$ in a one-tailed t-test) and that students with low pre-ECS confidence had significantly greater increases in interest if they had a CSexperienced teacher ( $p<.05$ in a two-tailed welch t-test).

The second area of difference was in the types of female students enrolled in the ECS classes. CS-experienced teachers were much more successful at recruiting female students who had greater confidence in their CS skills. The female students in CS-experienced teachers' ECS classes had significantly higher pre-ECS confidence in their understanding of CS concepts than female students in new-to-CS teachers' ECS classes. This may be due to CS-experienced teachers focusing more on recruiting female students from their other CS classes, or that CS-experienced teachers came from schools which offered more CS classes, and therefore had a larger pool of female students with high pre-ECS confidence. This finding is supported by the low number of female students with high confidence in courses taught by new-toCS teachers while female confidence is more uniformly distributed in courses taught by CS-experienced teachers, as is demonstrated in Figure 3.

\section{DISCUSSION OF CONTRIBUTIONS}

Our goal in starting this project was to make it easier for students to try their first CS courses and easier for teachers to try teaching CS. By lowering the stakes for both students and teachers, we have seen increases in student enrollment in CS classes and in the number of Utah CS teachers. Utah students can now meet a half-semester graduation requirement by taking ECS, without committing one of their few 
electives to CS unless their ECS experience motivates them to enroll in additional CS classes. With ECS as an entry point, Utah has broadened student participation to include more females and minorities in ECS and other computer science classes beyond ECS. The data in this paper support the premise that ECS is a stepping stone to other computer science classes that broadens participation.

Utah teachers are able to teach a half-year ECS course after participating in a small and manageable amount of professional development. More teachers, many of whom had no prior CS background, are now teaching entry level CS classes. Utah has broadened the number of schools and districts teaching computer science classes, including a number of smaller and more rural schools.

The new CS teacher pipeline described in this paper relies heavily on recruiting existing but new-to-CS teachers to CS. An analysis examining the ECS teachers, which includes most of these new-to-CS teachers, found little significant advantage for CS experience when teaching ECS. Regardless of their CS teachers' backgrounds, all students had similar self-reported gains in CS content and all students agreed by the end of their ECS courses that everyone could improve their CS skills. Students with low confidence in their own CS abilities reported significantly more interest in taking more CS classes if they had an experienced CS teacher. It is possible that other methodologies that do not use aggregate data [13] or that look at longer term learning gains [3] might be more sensitive and reveal additional differences between experienced CS teachers and new-to-CS teachers.

A comparison of the number of students and percentage of female students enrolled in Utah CS courses (Table 1) found ECS and AP CSP do appear to be better courses for attracting female enrollments than Utah's other CS courses (although it is too early to draw conclusions about CSP, which was first taught in Utah in 2015-16). The Utah ECS teachers also appear to successfully helping all students view $\mathrm{CS}$ with a growth mindset (i.e., anyone can improve). While we do not yet know if ECS students are more likely to take additional CS courses, Utah ECS students are self-reporting a significant increase in interest in taking more CS.

The growth in Utah ECS teachers has been accompanied by a slower by steady growth in CS Level 1 teachers (Figure 1). On average, one-third of these CS teachers' schedules are CS classes; two-thirds of their classes are classes in other areas. Finally, the vast majority of ECS teachers continue to teach CS courses after their first year of ECS.

\section{FUTURE WORK}

Utah is only starting the initial stages of creating a pipeline for K-8 CS teachers. The 2015-16 Utah Code.org partnership provided CS professional development to K-6 teachers from STEM schools and middle school science teachers, and we are exploring ways to leverage opportunities in K-8 STEM endorsement programs. While we have created a growing CS teacher pipeline for in-service secondary teachers, Utah is still lacking a pre-service CS education program. No Utah university has taught a CS-specific pedagogy course recently, which means a pre-service teacher would need to attend one of the ECS, CSP, and PLTW workshops that are currently substituting for the CS methods course. Establishing a CS pre-service teacher program is the critical next step in creating a sustainable CS teacher pipeline.

\section{ACKNOWLEDGEMENTS}

We are grateful for the contributions of the Utah and national ECS community and our evaluation team from SmartStart Evaluation and Research, especially Gail Chapman, Nicole Reitz-Larsen, Sarah Young, and Jessica Martone. This work is supported by the National Science Foundation Grants CNS-1240977, CNS-1228352, and CNS-1228355.

\section{REFERENCES}

[1] R. Adrion, R. Fall, B. Ericson, and M. Guzdial. Broadening access to computing education state by state. Commun. ACM, 59(2):32-34, Jan. 2016.

[2] O. Astrachan and A. Briggs. The CS principles project. ACM Inroads, 3(2):38-42, 2012.

[3] S. E. Carrell and J. E. West. Does professor quality matter? Evidence from random assignment of students to professors. Technical report, National Bureau of Economic Research, 2008.

[4] B. Ericson, M. Guzdial, and M. Biggers. Improving secondary CS education: Progress and problems. In Proceedings of the 38th SIGCSE Technical Symposium on Computer Science Education, SIGCSE '07, pages 298-301, New York, NY, USA, 2007. ACM.

[5] J. Gal-Ezer and C. Stephenson. Computer science teacher preparation is critical. ACM Inroads, 1(1):61-66, Mar. 2010.

[6] J. Goode and J. Margolis. Exploring computer science: A case study of school reform. Trans. Comput. Educ., 11(2):12:1-12:16, July 2011.

[7] N. Granor, L. A. DeLyser, and K. Wang. TEALS: Teacher professional development using industry volunteers. In Proceedings of the 47th ACM Technical Symposium on Computing Science Education, pages 60-65. ACM, 2016.

[8] H. H. Hu, C. Heiner, and J. McCarthy. Deploying Exploring Computer Science statewide. In Proceedings of the 47th ACM Technical Symposium on Computing Science Education, SIGCSE '16, pages 72-77, New York, NY, USA, 2016. ACM.

[9] K. Lang, R. Galanos, J. Goode, D. Seehorn, F. Trees, P. Phillips, and C. Stephenson. Bugs in the system: Computer science teacher certification in the US. The Computer Science Teachers Association and The Association for Computing Machinery, 2013.

[10] National Center for Women \& Information Technology. Counselors for Computing. https: //www.ncwit.org/project/counselors-computing-c4c, Retrieved August 2016.

[11] L. Ni and M. Guzdial. Who am I?: Understanding high school computer science teachers' professional identity. In Proceedings of the 43rd ACM technical symposium on Computer Science Education, pages 499-504. ACM, 2012.

[12] J. Wang, H. Hong, and S. H. Moghadam. Diversity in K-12 CS education across the U.S. In IEEE Research on Equity and sustained Participation in Engineering, Computing, and Technology (RESPECT) Conference, 2016.

[13] G. J. Whitehurst. Scientifically based research on teacher quality: Research on teacher preparation and professional development. In White House Conference on Preparing Tomorrow's Teacher, 2002. 